\title{
Evaluation of Genotoxicity of Lufenuron and Chlorfluazuron Insecticides in Drosophila melanogaster Using a Germ-Line Cell Aneuploidy and Chromosomal Aberrations Test
}

\author{
Jehane I. Eid ${ }^{1, a^{*}}$, Abdel-Fattah A. Awad ${ }^{b}$,Wesam T. Basal ${ }^{\mathrm{a}}$, Akmal A. El-Ghor $^{\mathrm{a}}$
}

\begin{abstract}
Acyl ureas, as insect growth regulators, were developed as "safe" and "non-mutagenic" insecticides. Here, using Drosophila melanogaster as a model system, three genotoxic modes of action of the acyl ureas were revealed. First, an adapted and modified genotoxicity test revealed genotoxicity in the germ-line cells of treated males. This was characterized as aneuploidy and chromosomal aberrations in brood 1 sperm of parental males that were inherited and appeared phenotypically at statistically significant rates $(P \leq 0.05)$ in $\mathrm{F} 1$ males. Second, damage to the entire genomic DNA, which was assessed in the adult fly of the isogenic strain $\mathrm{w}^{1118}$, was qualitatively indicated by an apoptosis-associated DNA fragmentation test. Apoptosis-specific internucleosomal cleaved fragments of 180-200 bp (and their multiples) were detected. DNA damage was also quantitatively estimated by the comet assay under a high alkaline condition $(\mathrm{pH}>13)$. From the tail moment criterion of this test, a statistically significant difference $(p<0.01)$ between the treated and untreated flies was observed. Third, we identified point mutations in specific fragments of the Dmp53 and $R b f$ tumor suppressor genes. Pairwise alignments of the obtained PCR products from pools of treated and untreated flies revealed the occurrence of point mutations as a genotoxic effect of acyl urea treatment. Based on these findings we propose that acyl ureas are multitudinous mutagens having three distinct mutagenic modes of action.
\end{abstract}

Keywords: Aneuploidy, Drosophila, Genotoxicity, Pesticides.

\section{INTRODUCTION}

$\mathrm{T}$ $\mathrm{HE}$ intensive use of insecticides leads to chronic exposure to lower doses of these toxicants, which may result in genotoxic stress in humans and other mammals [1]. Therefore, human genotoxicity and cancer risk because of exposure to insecticides represent a prominent hazard to public health. In response to DNA damage, mammals utilize distinct pathways such as apoptosis to obliterate or at least minimize the resulting hazards [2]. Defects in DNA damage response tend to cause genomic instability and may ultimately result in the formation of cancer [3].

\footnotetext{
${ }^{1}$ Department of Biology - Faculty of Applied Science - Umm Al-Qura University - 21421 - Makkah Al-Mukarramah - Kingdom of Saudi Arabia.

${ }^{\mathrm{a} Z}$ Zoology Department - Faculty of Science - Cairo University - 12613 Gizah - Egypt

${ }^{\mathrm{b}}$ Genetics Department, Faculty of Agriculture - Ain-Shams University 11566 - Cairo - Egypt
}

A new generation of safe (nonmutagenic) insecticides has been developed that disrupt the normal growth and development of insects and result eventually in the death of the insect pest [4]. Acyl ureas comprise a group of these insect growth regulators that are able to inhibit synthesis of insect chitin [5]. Most of the affected insects die from rupturing of the new malformed cuticle. Mechanisms of mutagenesis and risk assessment of the acyl ureas should be taken into consideration. This task can be accomplished by genotoxicity tests using genetic systems that detect mutations and their mode of formation [6]. Previously it was noted that no potential for mutagenicity was observed with lufenuron tested in vitro in bacteria (Ames test), in mammalian cells systems, and in vivo in a mouse micronucleus test and unscheduled DNA synthesis test with rat liver cells [7].

In this respect, Drosophila melanogaster is recommended as a model experimental animal because more than half of all D. melanogaster protein sequences are similar to those of mammals [8]. Furthermore, a direct homology between $D$. melanogaster genes and genes that affect human diseases (nearly $75 \%$ of genes that cause human diseases are believed to have a functional homologue in the fly) was also indicated $[9,10]$. Tester strains are available or can be constructed for determining almost all types of genetic changes, ranging from gene mutations to chromosome rearrangements, in a great variety of cell types of both sexes [11].

The genotype of the somatic aneuploidy test (SAT) strain, developed by [12], is $\mathrm{zw}-/ \mathrm{W}+\mathrm{Y}$ for the male and $\mathrm{zW}-$ homozygous for the female ( $\mathrm{W}$ - is the sex-linked mutation w11E4, which is a deletion of the white locus; $\mathrm{z}$ is the sexlinked mutation zeste). Both male and female are homozygous for the recessive mutation sepia eye (se) on the third chromosome. The Y chromosome carries a small piece of the $\mathrm{X}$ chromosome that includes the $\mathrm{w}+$ (the wild type gene of the color).

The $\mathrm{w}^{1118}$ flies have white eyes because of a deletion in the sex-linked white gene and therefore cannot revert to wild type. The white gene is normally located on the $\mathrm{X}$ chromosome, but it does not have to produce an eye color. Flies homozygous or hemizygous for $\mathrm{w}^{1118}$ have white eyes, whereas those heterozygous for $\mathrm{w}^{1118}$ and wild type have the normal red eyes. For aneuploidy and chromosomal aberrations, when germ-line cells are affected by this mutagenic mechanism, fetal abortions 
or offspring with typical syndromes are produced [13]. With D. melanogaster as a genetic model, there are certain mutagenicity test systems to detect aneuploidy and chromosomal aberrations in germ-line cells and in somatic cells, dominant lethal mutations, sex-linked and autosomal recessive lethal mutations, and translocations [14-16].

For detection and quantitative estimation of induced aneuploidy and chromosomal aberrations, germ-line cells of male $D$. melanogaster of a specific strain were used as a target for this task, and a D. melanogaster genotoxicity test was developed, standardized, and used. This developed test aims to be a feasible and reliable test for detecting inheritable mutations. Because DNA damage is a well-recognized inducer of carcinogenesis, the aim of this study was to reveal genotoxic modes of action of two of the acyl ureas insecticideslufenuron (LUF) and chlorfluazuron (CHLO) — and to assess their mutagenicity risks by using $D$. melanogaster as a genetic model.

First, DNA damage effects of both LUF and CHLO were assessed qualitatively using the developed strain of $D$. melanogaster by the DNA laddering assay and quantitatively by the comet assay. Second, the nucleotide sequence of certain fragments of the two highly familiar tumor suppressor genesDmp53 (variants b and c) and DmRbf-were examined for induced point mutations..

\section{METHODS AND MATERIALS}

\section{Chemicals}

LUF (1-[2,5-Dichloro-4-(1,1,2,3,3,3-hexafluoropropoxy) phenyl]-3-(2,6-difluorobenzoyl)urea) was purchased from Novartis Animal Health Inc. (USA), while CHLO (1-[3,5dichloro-4-(3-chloro-5-trifluoromethyl-2-pyridyloxy)phenyl]-

3- (2,6-difluorobenzoyl)urea) was purchased from Shijiazhuang Jitai Sanmu Pesticide Chemical Industry Co., Ltd. (China). Colchicine was obtained from El Nasr Pharmaceutical Chemicals (ADWIC) (Egypt).

\section{Strains}

The Drosophila strains used, SAT and $\mathrm{w}^{1118}$, were from well-established colonies at the Genetics Department, Faculty of Agriculture, Ain-Shams University, Egypt, and Zoology Department, Faculty of Science, Cairo University. The SAT strain was originated from Institute of Genetics, Biological Research Centre, H-6701 Szeged, Hungary. The $w^{1118}$ strain was originated from Bloomington Drosophila stock center (Stock no. 5905, FlyBase ID: FBst0005905).

The Drosophila SAT strain of genotype $\mathrm{zw}-/ \mathrm{w}+\mathrm{Y}$ for male and zw-/zw for female was used for the development of a germ-line cell aneuploidy test to be used for detection of the inheritable mutations. Flies from the isogenic strain $\mathrm{w}^{1118}$ (FlyBase ID: FBst0005905) were used for assessment of DNA damage and point mutations resulting from exposure to the tested putative mutagens.

All strains and crosses of normal and treated Drosophila were kept at a density of 100 flies per rearing bottle with controlled temperature at $25 \pm 1{ }^{\circ} \mathrm{C}$, a $16: 8 \mathrm{~h}$ light-dark photoperiod, and ambient relative humidity (40-70\%). Detailed descriptions of standard Drosophila colony and rearing techniques are given by [17]. One-day-old adult flies were collected from an established laboratory colony and then regularly transferred to freshly prepared medium every 3-4 days. One hundred flies were used in each experimental group.

Drosophila melanogaster strains were maintained on SDM (Standard Drosophila Medium) containing agar, corn meal, sucrose and yeast at $22 \pm 1{ }^{\circ} \mathrm{C}$ in laboratory conditions.

\section{Toxicity}

Seven concentrations $(10,15,20,25,30,35$, and $40 \mathrm{ppm}$ incorporated into the feeding medium) were used for determining the $\mathrm{LC}_{50}$ value for each insecticide. Third instar larvae $(n=100)$ were placed for $24 \mathrm{~h}$ into the rearing bottles containing a feeding medium incorporated with different concentrations of the acyl ureas. The concentration that caused $50 \%$ lethality of the flies was determined graphically using the log-probit analysis (Litchfield and Wilcoxon 1949). LC $_{50}$ was obtained by plotting probit survival against acyl ureas concentrations and fitting points by linear regression. The LC50 was determined to be $38 \mathrm{ppm}$ and $48 \mathrm{ppm}$ for LUF and CHLO, respectively.

\section{Treatment with acyl ureas}

Late third instar larvae (72-76 h aged) were exposed to the LC50 of the tested acyl ureas incorporated into the feeding medium for $24 \mathrm{~h}$. The treated larvae were floated from the feeding medium with $20 \%$ glycerol and transferred into new rearing bottles containing the normal feeding medium (no acyl ureas included) and held through pupation and then until adult emergence. Ten groups of 20-30 treated parental males were crossed with 40-60 normal untreated virgin females to obtain females inseminated with the first brood $(\mathrm{Br} 1)$ of sperm. The treated males were recrossed to new normal untreated virgin females under the same conditions to obtain females inseminated with the second brood $(\mathrm{Br} 2)$ of sperm. The daily emerged flies of this F1 progeny produced from the mentioned crosses were screened for the presence of abnormal progeny (i.e. white-eyed males or sepia-eyed females). Each abnormal male (white-eyed) was then separately crossed with four normal untreated virgin females to test whether it was fertile or sterile, as indicated from hatchability of the eggs laid by these crossed females. Treatment with the known aneugen colchicine was completed by immersion of the third instar larvae for $2 \mathrm{~h}$ in $1 \mathrm{mM}$ solution of this chemical, as recommended in [16, 18].

Development of a germ-line cell aneuploidy and chromosomal aberrations test

A specific D. melanogaster strain was originally developed for detection of somatic cell aneuploidy in parental male eyes as microscopic colored mosaics, (i.e., SAT) by [12]. In the present work, this test was modified and adapted to develop a genetic test for inheritable mutations, (i.e., germ-line cell aneuploidy and chromosomal aberrations test, or GAT) in parental males of $D$. melanogaster. These mutations appear as abnormal colors of the whole eye (a macroscopic phenotype) in the emerged males and females of F1 progeny because of exposure of the parental males as third larval instars to the $\mathrm{LC}_{50}$ of the acyl ureas LUF (38 ppm) and CHLO (48 ppm) for $24 \mathrm{~h}$.

This SAT strain, which has been adapted in the present work, is based on the observation of the eyes of the emerged 
parental males and detecting a few microscopic colored mosaics of yellow and white cell clones that represent XYY and XO cell descendants of a single XY cell (during development up to the formation of the parental adult male) in which nondisjunction took place in the developing eye primordium.

On the other hand, the color of the whole eye in the SAT strain of D. melanogaster is the trait of concern in the GAT test. The genetic structure controlling this trait is $\mathrm{w}-/ \mathrm{w}+\mathrm{Y}$; se/se in males and w-/w-; se/se in females. When the adult male or female carries only w-, it will have white eyes because of the lack of $w+$, which regulates eye pigment formation. The opposite is true with the adult carrying only $\mathrm{w}+$, which will have pigmented eyes. The recessive mutation se, located on the third chromosome, was originally introduced into the strain [19] to modify the colors. Therefore, when the w+ gene and two doses of se are present, as occurs in the normal males of this strain, a sepia-eyed phenotype is produced; otherwise, the eye color will be white, as in the normal females of this strain. Hence, GAT is based on the detection, in F1 progeny adults, of the abnormal phenotype sepia-eyed females (because of the presence of the nondisjunctioned $\mathrm{w}+\mathrm{Y}$ chromosome or its $\mathrm{w}+$ locus) and white-eyed males (because of the absence of the $\mathrm{w}+\mathrm{Y}$ chromosome or $\mathrm{w}+$ locus). Also, the sterility of the F1 male, which indicates the loss of the $\mathrm{X}$ or $\mathrm{Y}$ chromosome, is included as an abnormal case. Figure 1 shows eye colors of the normal male and female, and the GAT-produced mutated male and female D. melanogaster. Figure 2 shows scheme for the abnormal gametes produced by the treated parental males, the expected F1 progeny phenotype, and the mutation type.
A

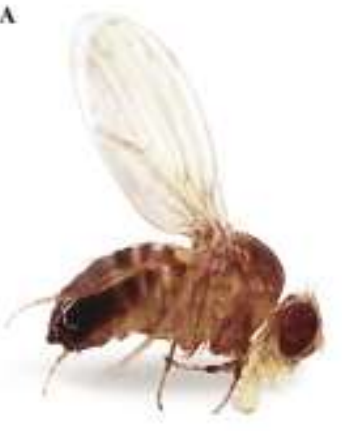

C

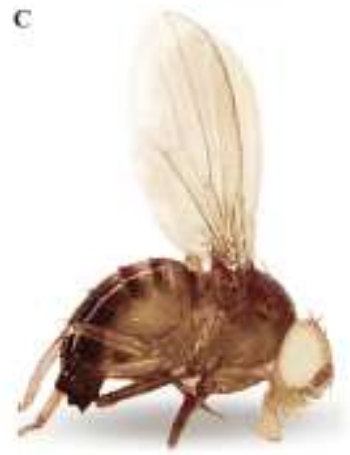

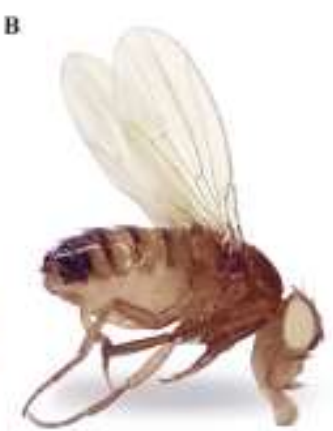

D
Fig. 1: Eye colors of the normal male (sepia-eyed, A) and female (white-eyed, B), and the GAT-produced mutated male (white-eyed, C) and mutated female (sepia-eyed, D) D. melanogaster

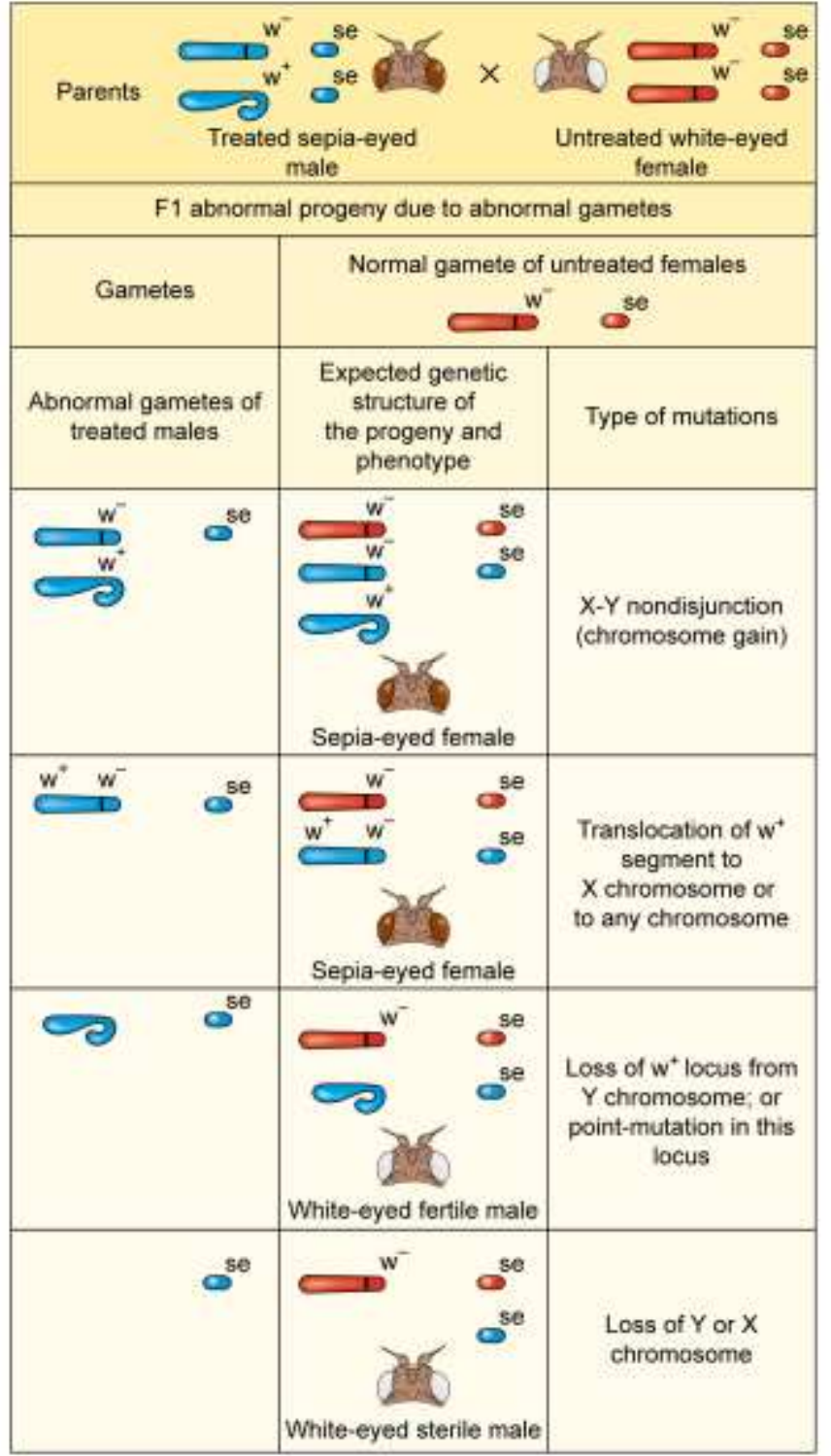

Fig. 2: Scheme for the detection and mode of aneuploidy and chromosomal aberrations in adult $D$. melanogaster using the developed GAT

The modification and adaptation of SAT to be used as GAT enables detection and quantitative estimation of the frequency of induced aneuploidy and chromosomal aberrations in male germ-line cells.

\section{Standardization of the developed GAT}

The validity of the developed GAT as a genotoxicity test for detecting aneuploidy and chromosomal aberrations in the germ-line cells of male D. melanogaster was tested. In this case, the known aneugenic chemical colchicine was used, as recommended by $[16,18]$ (see Materials and Methods). The obtained data show that colchicine has considerable aneugenic potential; it causes the production of white-eyed sterile (mutated) males and sepia-eyed (mutated) females with a highly significant difference $(p<0.001)$ when compared with that of the negative control.

Table 2 shows effect of LUF and CHLO on aneuploidy and chromosomal aberrations in germ-line cells of $D$. 
melanogaster, tested by GAT using chi-square statistics $\left(\chi^{2}-\right.$ test)

Therefore, GAT is a feasible and reliable test for the detection and quantitative estimation of the mutagenic potential of chemicals, such as the acyl ureas insecticides in this study, to induce aneuploidy and chromosomal aberrations in germ-line cells of parental male Drosophila. When GAT is compared with SAT, it is revealed to be more feasible and reliable for different parameters than SAT.

\section{Alkaline comet assay}

The extent of DNA damage in all types of cells of the isogenic strain $\left(\mathrm{w}^{1118}\right)$ of Drosophila adult that developed from the untreated and treated third larval instar was assessed. The adult flies were frozen in liquid nitrogen, around 100 flies were gently homogenized into powder, and then an alkaline comet assay as described by [20] was utilized.

Evaluation of DNA was visualized with fluorochrome stain of DNA with the fluorescent microscope and a 40X objective (depending on the size of the cells being scored). A Komet ${ }^{\mathrm{TM}}$ analysis system 4.0 developed by Kinetic Imaging, LTD (Liverpool, UK) linked to a CCD camera was used to measure the length of DNA migration (tail length, in $\mu \mathrm{m})(\mathrm{TL})$ and the percentage of migrated DNA (DNA \%). Finally, the program calculated tail moment. Fifty to one hundred randomly

TABLE 1: THE NUCLEAR SEQUENCES AND DROSOPHILA GENE ACCESSIONS NUMBERS ON WHICH THE DESIGN WAS BASED.

\begin{tabular}{|c|c|c|c|c|}
\hline Gene & Primers & Sequences & $\begin{array}{c}\text { Expected } \\
\text { product size (bp) }\end{array}$ & $\begin{array}{l}\text { Designing based on } \\
\text { accession no. }\end{array}$ \\
\hline \multirow[b]{2}{*}{$R b f$} & $\mathbf{F}$ & TCTGGCACATCTTTGAGCAC & \multirow[t]{2}{*}{233} & \multirow[t]{2}{*}{ NM_080297.2 } \\
\hline & $\mathbf{R}$ & CGGGTTGTAAGGAGTTGCAT & & \\
\hline \multirow[b]{2}{*}{ Dmp53b } & $\mathbf{F}$ & TGTATCGGGCGAAAAGAAAC & \multirow[t]{2}{*}{247} & \multirow[t]{2}{*}{ NM_206544.2 } \\
\hline & $\mathbf{R}$ & CTCGGCTATCATTGCTCTCC & & \\
\hline \multirow{2}{*}{ Dmp53c } & $\mathbf{F}$ & GGTGGCCACTACGATTCTGT & \multirow[t]{2}{*}{215} & \multirow[t]{2}{*}{ NM_001170223.1 } \\
\hline & $\mathbf{R}$ & AATTCCGATCCCGATACCTC & & \\
\hline
\end{tabular}

PCR amplifications were carried out using $2 \mu \mathrm{l}$ sample DNA extracts in a total volume of $50 \mu$ l. Reactions were carried out using the ready-made master mix DreamTaq DNA polymerase (Fermentas, Thermo Scientific) supplied in $2 \mathrm{X}$ DreamTaq Green Buffer. Samples were initially denaturated at $95^{\circ} \mathrm{C}$ for 5 min. PCR was monitored for 39 cycles with denaturation at $95{ }^{\circ} \mathrm{C}$ for $30 \mathrm{~s}$, annealing at $55^{\circ} \mathrm{C}$ for $30 \mathrm{~s}$ and elongation at $72{ }^{\circ} \mathrm{C}$ for $20 \mathrm{~s}$ were performed. A final extension at $72^{\circ} \mathrm{C}$ for 10 min was necessary for complete amplification.

The PCR products of the Dmp53 and DmRbf were cleaned up using a QIAquick PCR purification kit (QIAGEN, Germany). The purified PCR products were then subjected to DNA sequencing to determine mutations and the percentage of identities in nucleotide sequences of the amplified fragments of both Dmp53 gene variants and of $R b f$. The nucleotide sequences were determined by automated DNA sequencer 3730xl DNA analyzer from Applied Biosystems using BigDye ${ }^{\circledR}$ Terminator v3.1 cycle sequencing kit (Applied Biosystems). Nucleotide sequence analysis was performed with Genetyx software version 7.3.0 (GENETYX, Tokyo, Japan). The nucleotide homology search for the DNA sequence was performed by BLAST on the NCBI website (http://www.mbio.ncsu.edu/bioedit/bioedit.html).

\section{Statistical analysis} SPSS, Chicago, IL).

\section{RESULTS AND DISCUSSION}

selected cells were analyzed per sample (at least 25 cells per slide and 3 slides per treatment were evaluated). Three different parameters were used as indicators of DNA damage: tail moment (TM) (arbitrary units), tail DNA (\%), and tail length $(\mathrm{mm})$. These parameters have been described previously in detail [21].

\section{DNA fragmentation assay}

DNA from 50 flies was isolated using a salting-out extraction method as described by [22]. It was quantitated at $260 \mathrm{~nm}$, electrophoresed on a 1.5\% agarose gel in TBE buffer, and visualized after ethidium bromide staining using GelDoc XR (BioRad Laboratories, Inc).

\section{PCR amplification and sequence analysis}

A standard PCR protocol was applied on the extracted DNA pools from 50 flies from both the treated and untreated isogenic strain of Drosophila $\left(\mathrm{w}^{1118}\right)$ samples. Table 1 shows the sequences of the primers designed to amplify the target genes Dmp53 (two variants, Dmp53b and Dmp53c) and $R b f$. These primers were designed using Primer3 (http://www.ncbi.nlm.nih.gov/tools/primerblast/), obtained and synthesized from Bioneer (Seoul, Korea).

(http://blast.ncbi.nlm.nih.gov/Blast.cgi). Sequence alignment analysis was performed with the ClustalW program [23] and the BioEdit v7.1.3 program

Statistical analysis for comet assay data parameters (tailed cells, tail length, \% DNA, and tail moment) was done using one-way ANOVA. Data from five replicas of each group were analyzed, and the significance of difference was determined by GraphPad Prism® software (GraphPad Software, Inc., USA). Results of the germ-line cell aberrations test and the accompanying $p$ values were analyzed using chi-square statistics $\left(\chi^{2}\right.$-test) performed with SPSS software (version 15;

Referring to the genotoxic stress of the insecticide stressor, some effects, including several common mechanisms of mutagenesis, may be developed. These include formation of DNA adducts, damage to DNA structure, inhibition of DNA repair systems, and disturbance of genetic and cell cycle processes. Under these stressful conditions, apoptosis is triggered [24, 25]. To minimize LUF and CHLO risk to 
humans, these insecticides' identification, genotoxicity mechanisms, and risk assessment are necessary for the protection of public health.

The obtained data in the present work is outlined below in an attempt to shed some light on the genotoxic modes of action of the tested acyl ureas LUF and CHLO in D. melanogaster and also for risk assessment of these putative mutagens.

Assessment of germ-line cell aneuploidy and chromosomal aberrations

The quantitative evaluation of the mechanism of mutagenicity of the insecticides under investigation in the present work examined the deleterious effects of aneuploidy by using a test for germ-line cell aneuploidy and chromosomal aberrations (inheritable mutations) with $D$. melanogaster as a test animal. The eye color trait in D. melanogaster is the phenotype used as the indicator in this test; this is a sex-linked trait, and its gene is carried on the X chromosome [26].

Use of GAT for detection and quantitative estimation of mutagenicity of LUF and CHLO

It has been indicated that LUF and CHLO are not toxic to adult Drosophila but are toxic to larvae and pupae [27] because they act as anti-chitin formation compounds in these immature stages. The larvae and pupae have a clearly observed malformed cuticle that leads to death [28].

Crossing of the treated parental w-/w+Y males with untreated $\mathrm{w}^{-}$homozygous females, where both are homozygous for se, is expected to produce abnormal F1 progeny of the various phenotypes sepia-eyed female and fertile or sterile white-eyed males. Production of the referred phenotypes depends on the types of mutation occurring in sperm of the crossed parental males. These may include aneuploidy as a result of non-disjunction or loss of X- and Ychromosomes. Also, chromosomal aberrations may be included, such as loss of the w+ gene from the Y chromosome (or point mutation in this gene leading to loss of its function in eye pigmentation) or translocation of the $\mathrm{w}+$ segment to $\mathrm{X}$ - or any other chromosome.

When the developed GAT was used for assessment of the mutagenicity of the acyl ureas LUF and CHLO, cases of aneuploidy and chromosomal aberrations were detected and quantitatively estimated by comparison to a negative control. Also, colchicine-treated flies were used as a positive control, serving as an indicator for the validity of the test in each replicate. The data show that a significant number $(p<0.05)$ of F1 males having the abnormal white eye color resulted from Br1 germ-line cells of treated parental males. In contrast, this abnormality was not observed in $\mathrm{F} 1$ males produced from $\mathrm{Br} 2$ $(P>0.05)$. Also, the number of abnormal sepia-eyed F1 females produced from both $\mathrm{Br} 1$ and $\mathrm{Br} 2$ germ-line cells of treated parental males is insignificantly different from that of the negative control $(P>0.05$,$) .$

The mutagenic changes during spermatogenesis and production of certain abnormal gametes in parental males that lead to formation of F1 white-eyed fertile males seems to be caused by loss of the $\mathrm{w}+$ segment from the $\mathrm{Y}$ chromosome, or to point mutation in the $\mathrm{w}+$ gene itself, causing loss of its function in eye pigmentation. In contrast, the insignificant results of mutagenicity in F1 females (Table 2) indicate the insignificant production of abnormal gametes with $\mathrm{X}-\mathrm{Y}$ nondisjunction or with translocation of the $w+$ segment to any chromosome in parental males.

The results of GAT on treated parental male Drosophila in this study indicate that acyl ureas are mutagenic to the germline cells of $\mathrm{Br} 1$, but not to those of $\mathrm{Br} 2$. The occurring mutations are therefore inherited from parental males to males and females of F1 progeny.

In Drosophila (at $25^{\circ} \mathrm{C}$ ), spermatogenesis starts from the third larval instar and continues thereafter in pupae and adults; therefore, the emerged adult males have mature sperm [29, 30]. At the time of exposure of the parental third larval instar to LUF and CHLO, different developmental stages of spermatogenesis can be observed inside the sperm tubes (follicle). Therefore, during the first 5 days after emergence of these males, they inseminated the crossed untreated virgin females with the Br1 sperm that were in the maturation and reduction stages at the time of their exposure to LUF and CHLO. During this time, spermatocytes undergo the two meiotic divisions to produce spermatids and also the transformation of spermatids into spermatozoa. On the other hand, during the next 5 days after emergence, these males will inseminate the untreated virgin females with the Br2 sperm. These sperm were in the growth stage at the time of their exposure to LUF and CHLO, during which time the primary spermatogonia (enclosed in cysts) divide and increase in size to form spermatocytes.

Therefore, the germ-line cells undergoing the two meiotic divisions of $\mathrm{Br} 1$ are more sensitive to LUF and CHLO at the time of exposure, and exhibited mutagenic responses. This is in comparison to those of $\mathrm{Br} 2$, where they exhibited only mitotic divisions at the time of exposure. Hence, and according to the GAT used, it can be concluded that the acyl ureas insecticides LUF and CHLO tested in this study have variable mutagenic potential on the different stages of development of the germ-line cells of male Drosophila, causing aneuploidy and chromosomal aberrations. 
TABLE 2: EFFECT OF LUF AND CHLO ON ANEUPLOIDY AND CHROMOSOMAL ABERRATIONS IN GERM-LINE CELLS OF D. MELANOGASTER, TESTED BY GAT.

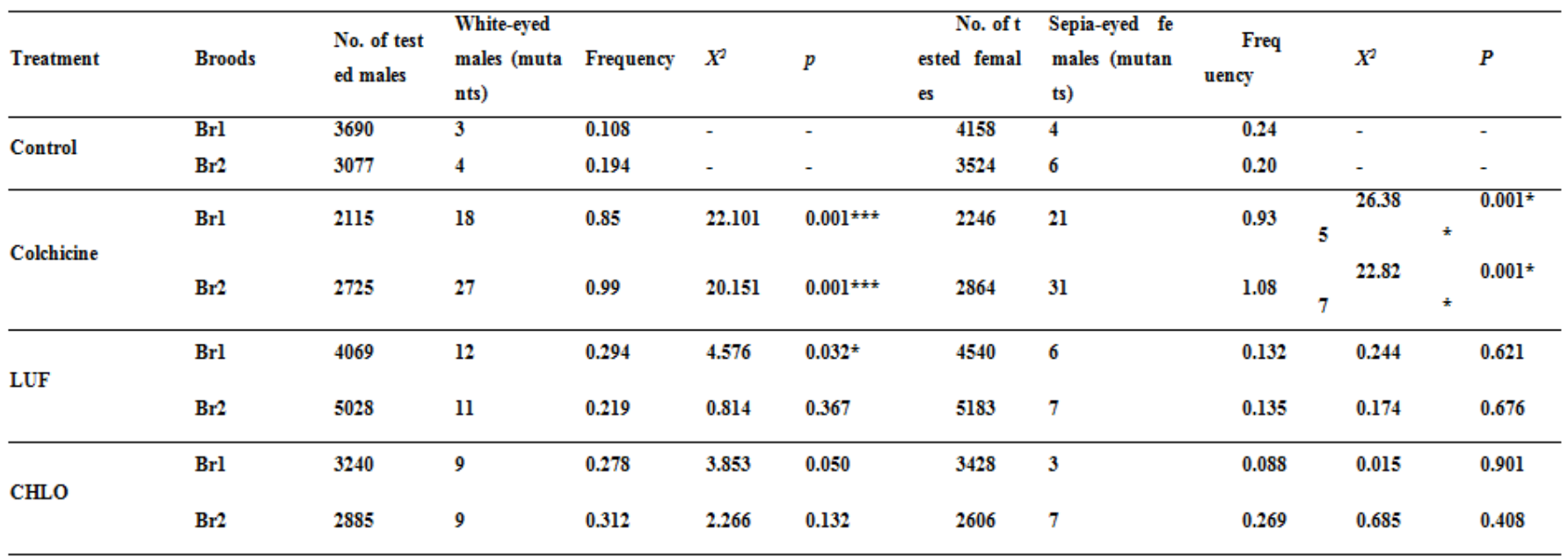

* significant, and *** highly significant, difference from the negative control at $p<0.05$ and $p<0.001$, respectively, using $X^{2}$-test.

\section{DNA damage}

DNA damage is considered a reflection of inadequate function of repair pathways in an organism that is a consequence of DNA adduct formation resulting in DNA strand breaks, formation of alkali-labile lesions, and crosslinks $[31,32]$. DNA damage (as a second genotoxic mode of action) in the whole body cells of the acyl ureas-treated adult $\mathrm{w}^{1118}$ strain Drosophila flies treated as third larval instars that were used in these assays was qualitatively detected by an apoptosis-associated DNA fragmentation test and also quantitatively estimated by the comet assay.

\section{Apoptosis-associated DNA fragmentation}

The genotoxic effect of the acyl ureas LUF and CHLO was further assayed qualitatively for apoptosis-associated DNA fragmentation in the whole body cells of treated parental adult Drosophila flies. Figure 3 shows the tested acyl ureas induced a ladder-like pattern of newly appeared electrophoretic bands on the agarose electrophoretogram of the whole genomic DNA extracted from acyl ureas-treated flies.

The results show that during apoptosis, cleavage of chromatin DNA into inter-nucleosomal fragments of 180-200 bp and multiples occurs [33]. In the case of treatment with LUF and CHLO acyl ureas, most of the new bands detected are around these molecular sizes and their multiples). These results suggest that treatment with the tested acyl ureas results in the chromatin DNA fragmentation characteristic of cells during apoptosis. As mentioned above, this is because of inadequate function of repair pathways; a condition that leads to induction of apoptosis [33].

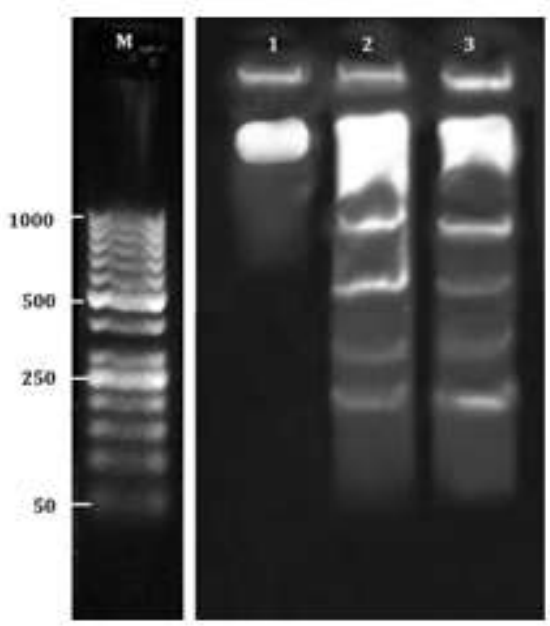

Fig. 3: Agarose gel electrophoresis of induced apoptosis-associated DNA fragmentation in the whole body cells of parental adult isogenic strain $w^{1118}$ Drosophila exposed as third larval instars to the LC50 of the acyl ureas LUF and CHLO incorporated into the feeding medium.

Lane M: 50 to 1000 bp DNA ladder (Fermentas); Lane 1: control genomic DNA; Lanes 2 \& 3: flies treated with LUF and CHLO, respectively.

\section{Single-cell gel electrophoresis; comet assay}

DNA damage was estimated quantitatively in whole body cells of acyl ureas-treated parental adult flies using an alkaline comet assay. Under these strong alkaline conditions $(\mathrm{pH}>13)$, the comet assay can quantitatively measure DNA damage in the form of single-strand breaks, double-strand breaks, alkalilabile sites (primarily apurinic and a pyrimidinic sites), incomplete excision repair sites, and DNA cross links [20]. The results are presented in Table 3, and the data include the tail length $(\mu \mathrm{m})$, percentage of DNA concentration in the tail, and the calculated tail moment, according to [20]. The obtained tail moment values of the treated parental flies are multiples those of the control flies with a highly significant difference $(p<0.01$ and $p<0.001)$ (Table 3). This indicates a high genotoxic potential capable of causing DNA damage in these insecticides. Therefore, we suggest also taking into consideration the number of tailed cells in comet scoring, as 
recommended by some authors [34, 35]; in this case, the indicated genotoxic potential could be verified.

Table 3 shows the quantitative evaluation of the DNA damage caused by LUF and CHLO in whole body cells of

TABLE 3: QUANTITATIVE ESTIMATION BY COMET ASSAY OF THE DNA DAMAGE, EXPRESSED AS TAIL MOMENT IN WHOLE BODY CELLS OF PARENTAL ADULTS OF THE ISOGENIC STRAIN $\mathrm{w}^{1118}$ OF DROSOPHILA EXPOSED AS THIRD LARVAL INSTARS TO THE LC50 OF THE ACYL UREAS LUF AND CHLO INCORPORATED IN THE FEEDING MEDIUM.

\begin{tabular}{ccccccc}
\hline Treatment & No. of samples & No. of cells observed & Tailed cells $\%$ & $\begin{array}{c}\text { Tail length } \\
(\mu \mathrm{m})\end{array}$ & Tail DNA \% & Tail moment \\
\hline Control & 5 & 500 & $4.4 \pm 0.24$ & $1.50 \pm 0.04$ & $1.61 \pm 0.06$ & $2.50 \pm 0.14$ \\
\hline LUF & 5 & 500 & $9.4 \pm 0.93^{*}$ & $5.89 \pm 0.91^{*}$ & $5.31 \pm 0.71^{*}$ & $43.24 \pm 5.98^{*}$ \\
\hline CHLO & 5 & 500 & $11.4 \pm 1.2^{* *}$ & $5.88 \pm 0.71^{*}$ & $5.77 \pm 0.98^{*}$ & $43.67 \pm 9.31^{*}$ \\
\hline
\end{tabular}

*Significant and **highly significant difference from the negative control $p<0.01$ and $p<0.001$, respectively.

\section{Specific gene mutations}

DNA damage resulting from genotoxic stress triggers transcription of genes that limit mutations and promote survival in organisms ranging from bacteria to humans [36]. These are the tumor suppressor genes (TSGs) in which a lossof-function mutation leads to cellular overproliferation [37]. TSGs are reported to be mutated in human cancers and can cause tumor susceptibility in mice [38, 39].

According to some reports, Drosophila contains a group of TSGs [40]. These latter are homologues of known human TSGs, including $P 53$ and $R b$, and are denoted as Dmp53 and $R b f$, respectively $[41,42]$. These vital TSGs (Dmp53 and $R b f$ ) were selected for assessment of mutations as a third mode of genotoxic action in parental adults of isogenic strain $\mathrm{w}^{1118}$ Drosophila because mutations in TSGs leads to an increased rate of resulting mutations under the effects of genotoxic stressors, which is required for DNA damage-induced apoptosis in Dmp53, but unlike the mammalian p53, Dmp53 44]. Two variants (b and c) of Dmp53 were selected in this study to reveal the expected mutagenesis in whole body cells of acyl ureas-treated parental adults. The sequences of the PCR-amplified fragments obtained from the treated samples were aligned, as opposed to the same fragment from the negative control samples (see supporting information). Examination of these sequence alignments shows that different mutations are observed, including substitutions, insertions, and deletions, and in some cases, long sequences of deletions were observed (see supporting information).

On the other hand, for $R b f$, the increased rate plays a critical role in the regulation of cell proliferation [45]. $\mathrm{Rb}$ protein plays an important role in the regulation of cell division, namely, cell death, and its activity is altered in most human tumors $[46,47]$. It is able to modulate the action of E2F transcription factors and regulate cell cycle progression [48]. The sequence of this PCR-amplified fragment of Rbf in treated flies obtained in this study was aligned, as opposed to that of the negative controls, as shown in supporting information file. This alignment reveals different mutations, including insertions, substitutions, and deletions. appears to be unable to block the cell cycle in G1 phase [43, parental adults of the isogenic strain $\mathrm{w}^{1118}$ of Drosophila using comet assay.
For the two genes Dmp53 and $R b f$, since pooled samples were used in the sequence analysis in this study, the obtained data are actually the summation of various mutations in different individuals. Therefore, the assessment of mutagenicity of LUF and CHLO in Drosophila, at the gene level, is considered qualitative, and does not show the actual frequency of mutation in individual flies. However, these qualitative results indicate the ability of these insecticides to cause mutations in the tested TSGs in the form of insertions, substitutions, and deletions of one or more nucleotides in the DNA strand. This can be considered, qualitatively, as an indication of the mutagenic potential of the used insecticides to the two TSGs. The occurring mutations in these TSGs may include loss-of-function mutations, leading to the observed levels of mutagenicity assayed in the form of DNA damage and as aneuploidy and chromosomal aberrations.

With regard to the physiology of the cell, more extensive binding has been found with transcriptionally active DNA, due to its open conformation [49]. Many, if not most, adducts have the potential to cause mutation [50]. Mutations arise either during DNA replication at the damaged sites or during DNA repair [51]. Hence, it can be assumed that the acyl ureas LUF and CHLO, as electrophiles, are able to form with DNA, as a nucleophile, DNA adducts. Therefore, they have multitudinous mutagenic potential to cause the observed mutations in Drosophila shown through the three indicated genotoxic modes of action: aneuploidy and chromosomal aberrations, DNA damage, and mutations in the selected genes.

The results of this study indicate the acyl ureas LUF and CHLO are genotoxic insecticides, and their genotoxic modes of action include aneuploidy and chromosomal aberrations, DNA damage, and point mutations. However, there have been claims that these acyl ureas are safe, nonmutagenic insecticides, specifically through the Ames test [52] on Salmonella [53, 54]. From the few available biochemical data [55-58], it is implied that the biochemical mode of action of acyl ureas is correlated directly or indirectly to regulatory proteins and their regulatory genes. Therefore, it could be hypothesized that acyl ureas are able to directly or indirectly cause multitudinous effects on the body macromolecules of Drosophila (and other insects), leading to interruption in performance of body physiology that eventually leads to death. 
It is worth mentioning that a direct homology exists between Drosophila genes and genes that affect human diseases, and a considerable conservation of genes and pathways affecting key biological processes between flies and humans exists $[8,59,60]$. Therefore, a homology to the deleterious genotoxic effects observed in Drosophila with this study may exist for humans exposed to acyl ureas from use of as insecticides, creating the hazard of genotoxicity and potentially also proteotoxic stresses.

\section{REFERENCES}

[1] T. C. Marrs, "Toxicology of insecticides to mammals," Pest management science, vol. 68, no. 10, pp. 1332-1336, 2012. https://doi.org/10.1002/ps.3362

[2] F. J. Bock, M. C. Tanzer, M. D. Haschka, G. Krumschnabel, B. Sohm, K. Goetsch, R. Kofler, and A. Villunger, "The p53 binding protein PDCD5 is not rate-limiting in DNA damage induced cell death," Scientific reports, vol. 5, pp. 11268, 2015. https://doi.org/10.1038/srep11268

[3] H. Tian, Z. Gao, Li H, Zhang B, Wang G, Zhang Q, Pei D, Zheng J. DNA damage response--a double-edged sword in cancer prevention and cancer therapy. Cancer letters. 2015 Mar 1;358(1):8-16. https://doi.org/10.1016/j.canlet.2014.12.038

[4] Yu SJ. The Toxicology and Biochemistry of Insecticides. London: CRC Press; 2008. 296 p.

[5] Pener MP, Dhadialla TS. An Overview of Insect Growth Disruptors; Applied Aspects. In: Dhadialla TS, editor. Advances in Insect Physiology. New York: Academic Press; 2012. p. 1-162. https://doi.org/10.1016/b978-0-12-391500-9.00001-2

[6] Federico C, Motta S, Palmieri C, Pappalardo M, Librando V, Saccone S. Phenylurea herbicides induce cytogenetic effects in Chinese hamster cell lines. Mutation research. 2011 Mar 18;721(1):89-94. https://doi.org/10.1016/j.mrgentox.2010.12.013

[7] EFSA Scientific Report. Conclusion regarding the peer review of the pesticide risk assessment of the active substance lufenuron 2008.

[8] Mackay TF, Anholt RR. Of flies and man: Drosophila as a model for human complex traits. Annual review of genomics and human genetics. 2006;7:339-67. https://doi.org/10.1146/annurev.genom.7.080505.115758

[9] Pandey UB, Nichols CD. Human disease models in Drosophila melanogaster and the role of the fly in therapeutic drug discovery. Pharmacological reviews. 2011 Jun;63(2):411-36. https://doi.org/10.1124/pr.110.003293

[10] Tseng JC, Chen HF, Wu KJ. A Twist tale of cancer metastasis and tumor angiogenesis. Histology and histopathology. 2015 Jun 18:11638.

[11] Park SY, Ludwig MZ, Tamarina NA, He BZ, Carl SH, Dickerson DA, et al. Genetic complexity in a Drosophila model of diabetes-associated misfolded human proinsulin. Genetics. $2014 \mathrm{Feb}$;196(2):539-55. https://doi.org/10.1534/genetics.113.157602

[12] Szabad J, Wurgler FE. A genetic assay to detect chromosome gain and/or loss in somatic cells of Drosophila melanogaster. Mutation research. 1987 Oct;180(2):201-6. https://doi.org/10.1016/0027-5107(87)90215-6

[13] Pacchierotti F, Eichenlaub-Ritter U. Environmental hazard in the aetiology of somatic and germ cell aneuploidy. Cytogenetic and genome research. 2011;133(2-4):254-68 https://doi.org/10.1159/000323284

[14] Würgler FE, Vogel EW. In vivo mutagenicity testing using somatic cells of Drosophila melanogaster. In: de Serres FJ, editor. Chemical mutagens: principles and methods for their detection. New York: Plenum Press; 1986. p. 1-72.

[15] Zimmering S, Mason JM, Osgood C. Current status of aneuploidy testing in Drosophila. Mutation research. 1986 Jan-Mar;167(1-2):71-87. https://doi.org/10.1016/0165-1110(86)90010-2

[16] Zimmering S, Osgood C, Mason JM. Aneuploidy in Drosophila, I. Genetic test systems in the female Drosophila melanogaster for the rapid detection of chemically induced chromosome gain and chromosome loss. Mutation research. 1990 Oct;234(5):319-26. https://doi.org/10.1016/0165-1161(90)90042-M
[17] Ashburner M. Drosophila: A laboratory handbook. Cold Spring Harbor Laboratory Press, New York: Cold Spring Harbor; 1989.

[18] Szabad J. A genetic assay for the detection of aneuploidy in the germline cells of Drosophila melanogaster. Mutation research. 1986 Oct;164(5):305-26. https://doi.org/10.1016/0165-1161(86)90002-6

[19] Becker HJ. Mitotic recombination. In: Ashburner M, Novitski E, editors. The Genetics and Biology of Drosophila. New York: Academic Press; 1976. p. 1019-87.

[20] Tice RR, Agurell E, Anderson D, Burlinson B, Hartmann A, Kobayashi $\mathrm{H}$, et al. Single cell gel/comet assay: guidelines for in vitro and in vivo genetic toxicology testing. Environmental and molecular mutagenesis. 2000;35(3):206-21. https://doi.org/10.1002/(SICI)1098-2280(2000)35:3<206::AIDEM8>3.0.CO;2-J

[21] Olive PL, Wlodek D, Durand RE, Banath JP. Factors influencing DNA migration from individual cells subjected to gel electrophoresis. Experimental cell research. $1992 \mathrm{Feb}$;198(2):259-67. https://doi.org/10.1016/0014-4827(92)90378-L

[22] Aljanabi SM, Martinez I. Universal and rapid salt-extraction of high quality genomic DNA for PCR-based techniques. Nucleic acids research. 1997 Nov 15;25(22):4692-3. PubMed PMID: 9358185. https://doi.org/10.1093/nar/25.22.4692

[23] Thompson JD, Higgins DG, Gibson TJ. CLUSTAL W: improving the sensitivity of progressive multiple sequence alignment through sequence weighting, position-specific gap penalties and weight matrix choice. Nucleic acids research. 1994 Nov 11;22(22):4673-80. PubMed PMID: 7984417 https://doi.org/10.1093/nar/22.22.4673

[24] Cimino MC. Comparative overview of current international strategies and guidelines for genetic toxicology testing for regulatory purposes. Environmental and molecular mutagenesis. 2006 Jun;47(5):362-90. https://doi.org/10.1002/em.20216

[25] Friedburg EC, Walker GC, Siede W, Schultz RA. DNA repair and mutagenesis. Second ed. Washington DC: ASM Press; 2006. 1118 p.

[26] Lindsley DL, Grell EH. Genetic variations of Drosophila melanogaster. Washington, DC: Carnegie Institution; 1968. 472 p.

[27] Dhadialla TS, Retnakaran A, Smagghe G. Insect growth- and development disrupting insecticides. In: Gilbert LI, Gill SS, editors. Insect Control. New York: Elsevier; 2010. p. 121-84.

[28] Ishaaya I. Insect Resistance to Benzoylphenylureas and Other Insect Growth Regulators. Molecular Mechanisms of Insecticide Resistance: American Chemical Society; 1992. p. 231-46. https://doi.org/10.1021/bk-1992-0505.ch019

[29] Hennig W. Spermatogenesis in Drosophila. The International journal of developmental biology. $1996 \mathrm{Feb} ; 40(1): 167-76$.

[30] Yamashita YM, Fuller MT, Jones DL. Signaling in stem cell niches: lessons from the Drosophila germline. Journal of cell science. $2005 \mathrm{Feb}$ 15;118(Pt 4):665-72. https://doi.org/10.1242/jcs.01680

[31] Nouspikel T. DNA repair in mammalian cells: So DNA repair really is that important? Cellular and molecular life sciences : CMLS. 2009 Mar;66(6):965-7. https://doi.org/10.1007/s00018-009-8737-y

[32] Jost P, Svobodova H, Stetina R. Induction and repair of DNA crosslinks induced by sulfur mustard in the A-549 cell line followed by a comet assay. Chemico-biological interactions. 2015 Jul 25;237:31-7. https://doi.org/10.1016/j.cbi.2015.05.009

[33] Di Filippo M, Bernardi G. The early apoptotic DNA fragmentation targets a small number of specific open chromatin regions. PloS one. 2009;4(4):e5010. PubMed PMID: 19347039. https://doi.org/10.1371/journal.pone.0005010

[34] Mouron SA, Golijow CD, Dulout FN. DNA damage by cadmium and arsenic salts assessed by the single cell gel electrophoresis assay. Mutation research. 2001 Nov 15;498(1-2):47-55 https://doi.org/10.1016/S1383-5718(01)00266-2

[35] Bilbao C, Ferreiro JA, Comendador MA, Sierra LM. Influence of mus201 and mus308 mutations of Drosophila melanogaster on the genotoxicity of model chemicals in somatic cells in vivo measured with the comet assay. Mutation research. 2002 Jun 19;503(1-2):11-9. https://doi.org/10.1016/S0027-5107(02)00070-2 
[36] Powell E, Piwnica-Worms D, Piwnica-Worms H. Contribution of p53 to metastasis. Cancer discovery. 2014 Apr;4(4):405-14. PubMed PMID: 24658082 .

https://doi.org/10.1158/2159-8290.CD-13-0136

[37] Spandidos DA. Oncogenes and tumor suppressor genes as paradigms in oncogenesis. Journal of BUON : official journal of the Balkan Union of Oncology. 2007 Sep;12 Suppl 1:S9-12.

[38] Spruck CH, Strohmaier H, Sangfelt O, Muller HM, Hubalek M, MullerHolzner E, et al. hCDC4 gene mutations in endometrial cancer. Cancer research. 2002 Aug 15;62(16):4535-9.

[39] Fuja TJ, Lin F, Osann KE, Bryant PJ. Somatic mutations and altered expression of the candidate tumor suppressors CSNK1 epsilon, DLG1, and EDD/hHYD in mammary ductal carcinoma. Cancer research. 2004 Feb 1;64(3):942-51. https://doi.org/10.1158/0008-5472.CAN-03-2100

[40] Menut L, Vaccari T, Dionne H, Hill J, Wu G, Bilder D. A mosaic genetic screen for Drosophila neoplastic tumor suppressor genes based on defective pupation. Genetics. 2007 Nov;177(3):1667-77. PubMed PMID: 17947427. https://doi.org/10.1534/genetics.107.078360

[41] Zhang C, Casas-Tinto S, Li G, Lin N, Chung M, Moreno E, et al. An intergenic regulatory region mediates Drosophila Myc-induced apoptosis and blocks tissue hyperplasia. Oncogene. 2015 Apr 30;34(18):2385-97. https://doi.org/10.1038/onc.2014.463

[42] Axelson H. Eyeing tumorigenesis: Notch signaling and epigenetic silencing of $\mathrm{Rb}$ in Drosophila. BioEssays : news and reviews in molecular, cellular and developmental biology. 2006 Jul;28(7):692-5 https://doi.org/10.1002/bies.20428

[43] Brodsky MH, Nordstrom W, Tsang G, Kwan E, Rubin GM, Abrams JM. Drosophila p53 binds a damage response element at the reaper locus. Cell. 2000 Mar 31;101(1):103-13. https://doi.org/10.1016/S0092-8674(00)80627-3

[44] Ollmann M, Young LM, Di Como CJ, Karim F, Belvin M, Robertson S, et al. Drosophila p53 is a structural and functional homolog of the tumor suppressor p53. Cell. 2000 Mar 31;101(1):91-101. https://doi.org/10.1016/S0092-8674(00)80626-1

[45] Elenbaas JS, Mouawad R, Henry RW, Arnosti DN, Payankaulam S. Role of Drosophila retinoblastoma protein instability element in cell growth and proliferation. Cell cycle (Georgetown, Tex). 2015;14(4):589-97. https://doi.org/10.4161/15384101.2014.991182

[46] Daria D, Filippi MD, Knudsen ES, Faccio R, Li Z, Kalfa T, et al. The retinoblastoma tumor suppressor is a critical intrinsic regulator for hematopoietic stem and progenitor cells under stress. Blood. $2008 \mathrm{Feb}$ 15;111(4):1894-902. PubMed PMID: 18048646. https://doi.org/10.1182/blood-2007-02-071746

[47] Wei Y, Mondal SS, Mouawad R, Wilczynski B, Henry RW, Arnosti DN. Genome-Wide Analysis of Drosophila RBf2 Protein Highlights the Diversity of RB Family Targets and Possible Role in Regulation of Ribosome Biosynthesis. G3 (Bethesda, Md). 2015;5(7):1503-15. PubMed PMID: 25999584. https://doi.org/10.1534/g3.115.019166

[48] Poznic M. Retinoblastoma protein: a central processing unit. Journal of biosciences. 2009 Jun;34(2):305-12. https://doi.org/10.1007/s12038-009-0034-2

[49] Poirier MC, Beland FA. DNA adduct measurements and tumor incidence during chronic carcinogen exposure in rodents. Environmental health perspectives. 1994 Oct;102 Suppl 6:161-5. PubMed PMID: 7889840. https://doi.org/10.2307/3432171

[50] Sassa A, Ohta T, Nohmi T, Honma M, Yasui M. Mutational specificities of brominated DNA adducts catalyzed by human DNA polymerases. Journal of molecular biology. 2011 Mar 11;406(5):679-86. https://doi.org/10.1016/j.jmb.2011.01.005

[51] Hutchinson F. Use of data from bacteria to interpret data on DNA damage processing in mammalian cells. Mutation research. 1989 MarMay;220(2-3):269-78. https://doi.org/10.1016/0165-1110(89)90031-6

[52] Maron DM, Ames BN. Revised methods for the Salmonella mutagenicity test. Mutation research. 1983 May;113(3-4):173-215. https://doi.org/10.1016/0165-1161(83)90010-9
[53] POPRC. Assessment of Alternatives to Endosulfan and DDT - A technical report. Stockholm Convention. available at: http://chm.pops.int/TheConvention/POPsReviewCommittee/Meetings/P OPRC7/POPRC7Followup/Requestsforinformation/Requestsforcommen tsbyPOPRC7IWGs/EndosulfanandDDTRequestforcomments/tabid/2743 /Default.aspx. 2012.

[54] PPDB. Pesticide Properties DataBase, http://sitem.herts.ac.uk/aeru/footprint/en/. 2013 Last retrieved: 2013-1017. Report No.

[55] Ishii S, Matsumura F. Diflubenzuron-induced changes in activities of the cAMP-dependent protein kinase in the newly molted integument of the American cockroach in situ and in cell free conditions. Insect Biochem Molec Biol. 1992;22(1):69-79. https://doi.org/10.1016/0965-1748(92)90101-J

[56] Nakagawa Y, Ishii S, Matsumura F. Diflubenzuron stimulates phosphorylation of a $39 \mathrm{kDa}$ integumental protein from newly molted American cockroach (Periplaneta americana). Insect biochemistry and molecular biology. 1996 Sep-Oct;26(8-9):891-8. https://doi.org/10.1016/S0965-1748(96)00048-3

[57] Oberlander H, Silhacek DL. New perspectives on the mode of action of benzoylphenyl urea insecticides. In: Ishaaya I, Degheele D, editors. Insecticides with Novel Modes of Action: Springer; 1998. p. 92-105. https://doi.org/10.1007/978-3-662-03565-8_6

[58] Salokhe S, Sarkar A, Kulkarni A, Mukherjee S, Pal KP. Flufenoxuron, an acylurea insect growth regulator, alters development of Tribolium castaneum (Herbst) (Coleoptera: Tenebrionidae) by modulating levels of chitin, soluble protein content, and HSP70 and p34cdc2 in the larval tissues. Pest Biochem Physiol. 2006;85(2):84-90. https://doi.org/10.1016/j.pestbp.2005.10.006

[59] Koh K, Evans JM, Hendricks JC, Sehgal A. A Drosophila model for age-associated changes in sleep:wake cycles. Proceedings of the National Academy of Sciences of the United States of America. 2006 Sep 12;103(37):13843-7. PubMed PMID: 16938867. https://doi.org/10.1073/pnas.0605903103

[60] Marsh JL, Thompson LM. Drosophila in the study of neurodegenerative disease. Neuron. 2006 Oct 5;52(1):169-78. https://doi.org/10.1016/j.neuron.2006.09.025 